\title{
The 'Sharing Trap': A Case Study of Societal and Stakeholder Readiness for On-Demand and Autonomous Public Transport in New South Wales, Australia
}

\author{
Sigma Dolins ${ }^{1, *(\mathbb{D})}$, Yale Z. Wong ${ }^{2}(\mathbb{D})$ and John D. Nelson ${ }^{2}(\mathbb{D}$ \\ 1 RISE Research Institutes of Sweden, 41323 Gothenburg, Sweden \\ 2 Institute of Transport \& Logistics Studies, University of Sydney Business School, Sydney, NSW 2006, \\ Australia; yale.wong@sydney.edu.au (Y.Z.W.); j.nelson@sydney.edu.au (J.D.N.) \\ * Correspondence: sigma.dolins@ri.se
}

check for

updates

Citation: Dolins, S.; Wong, Y.Z.; Nelson, J.D. The 'Sharing Trap': A Case Study of Societal and Stakeholder Readiness for On-Demand and Autonomous Public Transport in New South Wales, Australia. Sustainability 2021, 13, 9574. https://doi.org/10.3390/su13179574

Academic Editors:

Gonzalo Fernández-Sánchez, Rafael Cortes and Marc A. Rosen

Received: 15 July 2021

Accepted: 21 August 2021

Published: 25 August 2021

Publisher's Note: MDPI stays neutral with regard to jurisdictional claims in published maps and institutional affiliations.

Copyright: (c) 2021 by the authors. Licensee MDPI, Basel, Switzerland. This article is an open access article distributed under the terms and conditions of the Creative Commons Attribution (CC BY) license (https:// creativecommons.org/licenses/by/ $4.0 /)$.

\begin{abstract}
Focus groups on shared, autonomous vehicles (SAVs) in New South Wales expressed "sharing anxiety" - an intense concern about the prospect of sharing their mobility journey with strangers, without a driver or authority figure present. This presents a significant barrier to the acceptance of SAVs, particularly autonomous public and on-demand transport (ODT), which is a major focus for Transport for New South Wales (TfNSW). Given this potential barrier, we interviewed $(\mathrm{N}=13)$ operators, academics, and regulators with TfNSW to assess their role and abilities in overcoming sharing anxiety. However, our findings revealed a relative lack of awareness from experts in the mobility industry about the existence of sharing anxiety in users, suggesting additional barriers to adoption. We make suggestions for policy considerations for stakeholders that could mitigate sharing anxiety: promoting dynamic ridepooling products in commercial services, using tax breaks as incentivization; requiring ODT services and operators in jurisdiction to use a standardized, unified interface for users ("single-app"); shared, on-demand transport services likely need longer incubation/pilot periods in order for the sharing behavior to become culturally established. We conclude with a reflection on how COVID-19 has impacted the development of shared mobility and suggest further exploration in policy implementation.
\end{abstract}

Keywords: sharing anxiety; demand responsive transport; autonomous vehicles; autonomous public transport; transportation policy

\section{Introduction}

On-demand transportation services like Uber, providing affordable and flexible rides, have dominated public awareness in the last few years. As development and deployment on autonomous vehicles continues, the transportation industry has been envisioning what might be the future of mobility. Fulton et al. (2017) [1] examined different implementation scenarios, and found that while there were significant environmental benefits from electric and autonomous transport, such as reduction in vehicles on the road, reductions in greenhouse gas emissions, and increase in road user safety, the greatest benefits emerge from the scenario where electric and autonomous transport is shared, which could reduce the cost of the urban transportation system (infrastructure, vehicles, and operations) by as much as $40 \%$. However, despite studies confirming the need for shared autonomous vehicles (SAVs), much of the technology and vehicle industry's focus remains on creating autonomous vehicles and services for private use.

There are significant risks to introducing new mobility technology without considering its impact on socio-technical systems. In Morris' (2007) [2] overview of the evolution of the automobile it is shown that public authorities could not envision how the automobile would radically alter human life patterns, urban form and the environment. Decades later, we deal with the externalities of that invention in the form of air pollution, urban 
sprawl, changed social mores and unsafe intersections [3]. If AVs are introduced without established norms and behaviors about how to share the asset of a vehicle space-if people do not use AVs similar to how they use public transport-Fraedrich et al. (2019) [4] argue that $\mathrm{AVs}$ would be seen and used as a private good, leading to significant problems with increased demand and increased congestion. Such an outcome will not only cause problems in already congested areas, but there could be long-term implications for urban sprawl, worsened socio-economic stratification, and a sharp decrease in public transport ridership.

Since the original form of affordable and shared rides was public transportation, a government-provided and managed public good, it seems a natural conclusion that AVs need to be developed and planned for as public transportation's next technological evolution: shared, autonomous public transport.

Yet, there are still gaps and inconsistencies in how we conceptualize and plan for shared mobility, and this is a complex challenge only further confounded by the COVID-19 global pandemic. It is arguable that both the mobility industry and government have overlooked how certain behaviors and services could be prerequisites for a transition into using vehicular technology and avoiding unintended consequences of new mobility offers. For example, there is evidence compiled by Sarriera et al. (2017) [5] that users of contemporary on-demand ridehailing and shared mobility services already experience heightened tension or reluctance to share with other people in the vehicle, even with the incentive of a reduced price for travel.

In our earlier research, we conducted focus groups with users in New South Wales, Australia, to understand their feelings about on-demand transport, ridehailing, dynamic ridepooling, AVs, and SAVs. While much new research is emerging on sharing in ondemand mobility contexts [5-8], prior research into users and AVs has primarily focused on acceptance of driverless vehicles and not the act of sharing them. The results of our focus groups suggested that one of the biggest barriers to the adoption of SAVs lay not in technological acceptance, but in "sharing anxiety": driverless vehicles present an authority vacuum, creating concern and apprehension about the potential misbehavior of other riders [9]. This presented a significant barrier to the development of shared, on-demand autonomous public transport.

The emergence of ride-sharing and ridepooling creates a responsibility for governments and other stakeholders to give proper attention to land transportation policy and to enhance efficiency of existing systems to make them proactive. Drawing from this context, it is clear that sharing anxiety must be addressed in order to promote and develop this technology for public use, especially in shared formats. This means that it is crucial to evaluate perspectives of experts that will implement this future policy of AVs.

This paper seeks to answer the following questions:

I. What do transportation experts believe customers expect from future shared or autonomous public transport?

II. Who do transportation experts believe is responsible for encouraging or increasing willingness-to-share amongst the public, when it comes to AVs?

III. How could transportation stakeholders increase societal acceptance of dynamic ridepooling, in preparation for a shared AV future?

This paper summarizes the findings from transport expert interviews with strategists, operators, academics and regulators, and looks more deeply at on-demand dynamic ridepooling policy and potential shared AV policy. By systematically comparing other nations' policy measures regarding on-demand ridehailing, AV mobility, and TfNSW's stated objectives for both, we highlight areas that require more attention from the state authorities and provide recommendations for new policies whose implementation would increase community acceptance for shared mobility. The findings reported in this paper form part of a larger series of socio-technical research into factors that affect societal readiness for shared autonomous public transport at the individual and regional level, The Societal Readiness Index for Shared Autonomy. 
The paper is organized as follows. The next section will address commonly used mobility terms and services around the world, review the scientific literature around shared mobility and on-demand mobility, and reflect on the present uncertainties around people's propensity to share in small vehicle and autonomous vehicle contexts. The third section presents the case study of New South Wales as an ideal environment to study these key questions. The fourth section explains the methodology around the expert interviews. The fifth section presents the results of the interviews, and the sixth and final section presents policy recommendations and conclusions for next approaches to the research.

\section{Review of Literature}

\subsection{Definitions}

According to Metz (2018) [10], there are two aspects to vehicle sharing: shared ownership of the vehicle asset and shared use of the vehicle space by unrelated people on a particular journey (shared use by friends, family and work colleagues is routine). We begin with categorizing the most common forms of shared mobility according to the level of personal control (i.e., does the user "drive" the vehicle, or are they a passive rider?) and the number of persons who can use that modality (i.e., short-term bike rentals are usually for one person, whereas on-demand public transport vehicles usually accommodate 8-15 people). We attempted to organize a scale of contemporary shared mobility options, below in Figure 1.

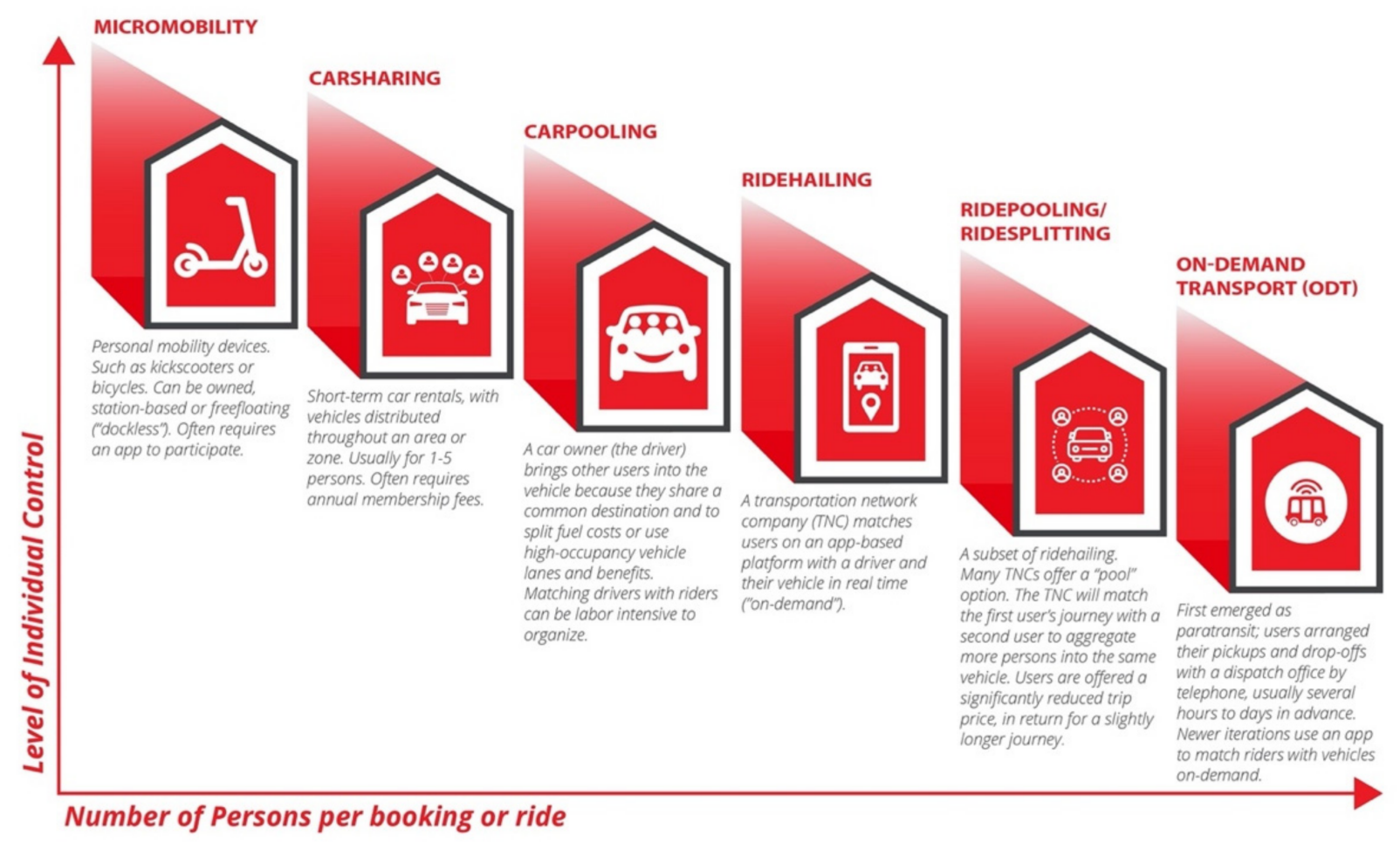

Figure 1. A scale of contemporary shared mobility options, with varying degrees of individual control over route and passenger capacity.

The word "ridesharing" connotates that the driver and passenger(s) share the same, or at least nearby final destinations, thereby reducing the number of cars and hence net road space required to complete the journey of at least two separate parties. Technically, this would be considered carpooling. However, TNCs tend to abuse the use of "sharing" and its carpooling connotation, since the drivers are usually contracted workers who are completing transportation trips for users as customers, and not because of any shared end destination. "Ridesharing" was frequently used as a popular colloquial term for 
describing all ridehailing services when they first were introduced to the market, which led to significant confusion when "pooled" options became available.

In some cases, Neoh et al. (2017) [11] and Wong, Hensher, and Mulley (2020) [12] established that this misunderstanding can be beneficial for TNCs and contractor drivers, because certain markets (such as the United States) have existing carpooling interventions that support shared mobility, in the form of high occupancy vehicle (HOV) lanes, better insurance coverage for the driver, or even taxation deductions.

Of the articles reviewed for this study, 13 used the term "dynamic rideshare" or "dynamic ride-share" to identify the sub-set of ridehailing services that expand on the typical on-demand matching of taxis or TNCs to potential riders, and in a trade-off of convenience and price, place multiple riders in the same vehicle. Sanguinetti et al. (2019) [8] as well as Bansal et al. (2019) [13] used the term "ridepooling" or "ride-pooling" to cover the same service and behavior type as other authors call "dynamic ridesharing".

In 2018, SAE International deprecated the term "ridesharing" entirely, due to its widespread use to refer to a variety of distinct and different mobility contexts, causing confusion over its meaning and referral [14]. In this article, we refer to on-demand rides with a single booking in the vehicle as "ridehailing", and multiple bookings in a vehicle (with a capacity for less than 15 persons) as "ridepooling".

\subsection{Literature on AVs, Ridepooling, and Sharing Policies}

$\mathrm{AVs}$ represent a potentially disruptive yet beneficial change to the transportation system [15]. AV technology, coupled with ridepooling, has the potential to positively impact passenger occupancy, reduce number of vehicles needed in the transport network, relieve congestion, protect air quality, lower vehicle emissions, and reduce the need for infrastructure investment [16]. While Dia and Javans (2017) [17] as cited in Barbour, N., Menon, N., Zhang, Y., and Mannering, F., (2019) [18] stated that incorporating shared automated vehicles as a modal option can significantly reduce the total number of vehicles required to meet the transport needs of a community, vehicles will need to be regulated further if congestion worsens.

At the forefront, shared use increases car occupancy, which would be expected to reduce the number of cars needed to meet the travel needs of a given population; however reduced congestion would tend to attract trips previously deterred by anticipated delays, and AVs offer the potential to drive "empty" to pick up passengers [10]. Effective regulation is essential to ensure that $\mathrm{AVs}$ will not contribute to the problem that they are seeking to resolve; empty AV travel may need to be statutorily limited below the level of the average public opinion [11]. Metz (2018) [10] suggests that authorities will need to address the implications of a growing population of vehicles with varying levels of automation and for cities to manage the urban deployment of AVs.

Fraedrich et al. (2019) [4] point to the likelihood that individuals will expect to use AVs like they use their privately owned cars. This potential view, AVs as a private household good and not a shared product, could lead to significant problems, including threatening traditional public transport systems - unless the government and transit agencies move to incorporate it. The government now has the option to provide new opportunities to revitalize micro-enterprises and even provide new sources of revenues for the state [19]. However, it is dependent on the government being able to attract users to a shared, autonomous public transport system.

Before being able to share rides, people need to be comfortable enough to use the technology. Past studies by Barbour et al. (2019) [18] with users of on-demand mobility and potential users of AVs identified their top three concerns as safety, reliability, and privacy. To increase sharing means being able to convince road users that these vehicles are safe enough to use, that the services are reliable enough, and that they can be confident in a pleasant experience within the vehicle.

According to Fagnant and Kockelman (2015) [15], "liability details remain undefined, security concerns linger, and without new privacy standards, a default lack of privacy for 
personal travel may become the norm" in the ridehailing economy. Further, the authors claim that impacts and interactions with other components of the transportation system, as well as implementation details, remain uncertain which hinders people from using shared transportation. Particularly, safety in dynamic ridepooling is an important issue, especially for women, many of whom report feeling unsafe and prefer to be matched with passengers of the same sex [6].

Our earlier work in New South Wales found that there is evidence that a barrier to the adoption of SAVs lies "in the concerns of riders about other riders, or potential emergency situations when the presence of an authority figure (the driver) is removed, leading to 'sharing anxiety'" [9]. Sharing anxiety, coupled with distrust of technology, makes it more difficult for users to share rides. The Greenwich MERGE Project (2018) in London had similar findings and suggested that future services would have to devise a way to allow customers to contact the technology provider while inside an AV, in order for them to feel safe [20].

While Ho et al. (2018), Lavieri and Bhat (2019) and Delbosc et al. (2019) established that millennials and technology enthusiasts have higher willingness-to-share with services such as dynamic ridepooling or in an AV context [21-23], it is not yet clear if this is the only demographic likely to embrace shared AVs. Without a clear understanding of which demographics or communities would accept dynamic ridepooling and what factors influence their willingness-to-share, shared mobility modes like on-demand transport or shared autonomous public transport may be de-prioritized in future urban and transportation planning. Cohen and Shirazi (2017) caution that failure to support shared mobility is "both an equity issue, since low-income commuters are more reliant on transit and other shared modes, and one of increasing transportation efficiency overall" (p. 4) [24].

Previous research on the adoption and implementation of AVs has tried to anticipate the infrastructure and societal changes required for the smooth public introduction of AVs, including examining how civic stakeholders are approaching relevant social issues. Fagnant and Kockelman (2015) [15] distilled policy recommendations into three actions: expand United States federal funding for autonomous vehicle research; develop federal guidelines for autonomous vehicle certification; determine appropriate standards for liability, security, and data privacy.

Interestingly, although safety was discussed, the focus of safety policies remained technologically biased; "regardless of how safe AVs eventually become, there is likely to be an initial perception that they are potentially unsafe because the lack of a human driver" [15]. Safety concerns that potential users may have had about non-technical matters, such as the presence of other riders in their shared AV, and policies to address these issues, were absent and in later research, rarely discussed. It is believed that it is relevant for users to have a "direct experience of AVs" along with education/communication to help change individuals" attitudes towards AVs and convince "skeptical clusters of their merits, and thus change people's attitudes towards AVs in a positive way" [6].

Previous research has identified the need to look into meaningful market penetration estimates of different AV scenarios, to provide transportation planners and policymakers with a reasonable range of outcomes for evaluating competing infrastructure investments, AV policies, and other policy decisions $[15,25,26]$. However, previous research on the topics of ridehailing and dynamic ridepooling, such as the work of Zhao (2017), Sarriera et al. (2017) and Sanguinetti, Kurani, Ferguson (2019) explicitly acknowledge the need for policy to support the widespread acceptance of shared AVs and shared mobility, but struggled to concretely point to instances where a government stakeholder was already implementing supportive shared mobility policies, or was focusing on growing acceptance of shared mobility $[5,6,8]$.

Fraedrich et al. (2019) focused on surveying and interviewing urban transport planning authorities in Germany [4]. While their literature review showed that autonomous driving has the potential to affect the built environment such as the required road space, infrastructures, mobility, and land use, the study revealed that only a portion of the ex- 
perts believed AVs could contribute positively to urban planning goals. By being shared, "overall, positive effects induced by automation were only expected with regard to objectives deemed as less important in the previous block, such as increasing traffic safety, and improving traffic flow and infrastructure capacity (p. 11)."

Smith and Hensher (2020) state that there must be reforms on passenger transport regulations from prescribing which vehicles, technologies, and business models that transport technology providers (contracted and otherwise) should use [26]. These include the transformation of how public transport operator contracts are tendered, and what components the contracts include and the modification of previous regulations related to transport. To ensure AVs are following the specified format on dynamic ride-pooling, it is important these are government-regulated and agreed upon by private sector partners.

Narayanan, Chaniotakis, and Antonioua (2020) state that "policy makers have to understand the nuances of these and carefully foster the deployment of autonomous vehicles", including their interaction with general traffic [25]. Additionally, enough understanding is needed in terms of AV deployment and synching policy decisions as there is a greater risk of unsustainable growth of SAV services or the continuous use of private vehicles [25].

The literature suggests to involve stakeholders in the planning process and to align policy efforts towards the integration of $\mathrm{AVs}$ into the public transport system; however, it also suggests that there is a need to investigate the relationship between safety level and segment of the population that intends to use autonomous vehicles. Further, people are likely to decide to adopt different types of AV ownership (private, shared ownership, shared use, etc.) which can be influenced by the individual factors as well [27]. These factors affect an individual's willingness-to-share in transport. Thus, there is a need to investigate ways as to how people can be attracted to share rides, in contemporary and future mobility offers. This paper will look into these policy gaps and assess perspectives of transportation stakeholders in addressing the crucial barrier of "sharing anxiety" [9].

\section{Methodology}

\subsection{Case Study Selection: New South Wales}

This research focused on New South Wales, Australia, where the state has been extremely progressive in implementing pilot projects in the areas of both on-demand public transport and autonomous vehicles, demonstrating a willingness to innovate and test AVs outside of the metropolitan and urban contexts and putting trials in rural and regional areas to emphasize their role as transport for disadvantaged riders. As an example, TfNSW enabled more flexibility for transport contracts in order to leave room for both fixed route and on-demand services in a single contract offering. The Future Transport 2056 strategy (discussed in detail in Section 3 below) included a series of innovative commitments and regulatory reforms. For example, their initial On-Demand Transport (ODT) program aimed to attract partnerships from incumbent public transport operators, technology providers (which include vehicle manufacturers). TfNSW sought to implement pilots in areas that had poorly patronized fixed route service, regions where off-peak services were sub-optimal, and first/last mile connections that would support increased ridership on trunk routes.

There has also been significant involvement from multinational as well as local transport operators. New South Wales has engaged in multiple ODT schemes using app-based bookings and real time routing. By doing so, the state embarked on a comprehensive strategy of regulatory reform and investment to prepare for the widespread adoption of new technologies, including some of the world's most comprehensive trials of both autonomous shuttles and on-demand public transport.

In March 2018, New South Wales released an ambitious transport reform strategy, known as Future Transport 2056. In this document, the New South Wales Government outlined five key goals and strategies for the coming decades, two of which explicitly refer to shared and autonomous transport with the intention to "foster shared, demandresponsive services: enabling flexible, shared use service models" and "enable connected 
and automated vehicles (CAVs): supporting vehicles and enabling infrastructure that improves mobility services, efficiency, reliability and safety".

The plan connected these two strategic goals together several times, noting that "if connected AVs are predominantly used to run shared services, they could also help reduce congestion and get more people out of their cars by extending the catchment of traditional public transport systems" [28].

To realize this intention, TfNSW began intensively working with industry partners to undertake testing of these technologies and understand its benefits to the transport network. The first precinct-based trial of an automated shuttle in Australia was launched in September 2018 at Sydney Olympic Park. Regional automated vehicle trials are currently held in Armidale, Newcastle, and Coffs Harbour; the BusBot in Coffs Harbour was launched in December 2018 and Newcastle's driverless shuttle was made available in November 2019. "Ardi", Armidale's driverless shuttle (which was fondly called EZ10 or "the Toaster" by students) first began operation in February 2019.

In terms of ODT, the 20+ trials and pilots are funded by TfNSW as part of a transport system innovation program; part of which targeted areas that were challenging to offer traditional public transport, such as the Northern Beaches and Macquarie Park, due to physical constraints such as narrow, un-gridded streets or relatively low housing density.

New South Wales is thus a noteworthy case study of attitudes towards shared and emerging mobility. The investigations reported here offer insights into the future requirements of supporting technology and infrastructure, as well as understanding passengers' responses for shared $\mathrm{AV}$ acceptance and how it can fit in to a broader transport network. In our analysis, we will compare other nations' policy measures regarding on-demand ridehailing, AV mobility, and TfNSW's stated objectives, and highlight areas that require more attention from the State authorities and provide recommendations for new policies whose implementation would increase community acceptance for shared mobility.

\subsection{Recruitment of Interviewees}

A total number of 13 participants were interviewed from October 2019 to February 2020: six transport operators, two representatives from TfNSW, two representatives from the Point-to-Point Transport Commission (within TfNSW), two technology providers (in this case, AV manufacturers) and one academic. It was decided to take a qualitative, conversational interview approach. While the sample size of interviewees is relatively small, we felt that the participants covered a wide range of perspectives throughout New South Wales, and were already working together to develop autonomous and on-demand mobility projects in their professional capacities, and therefore could present a strong picture of the current situation in New South Wales.

Participants were recruited using chain referral sampling (defined by Biernacki and Waldorf (1981) as 'snowball sampling') through the co-operation and support from TfNSW, as well as through the University of Sydney's Institute of Transport and Logistics Studies network [29]. This is an approach that focuses on asking people already within the network or scope of co-operation on the topic of autonomous vehicle development or mobility to agree to an interview, and then to ask these individuals to suggest or identify other people they know or collaborate with for future interviews with the research team. This method works well in specialized populations, such as the transport industry, where many entities work with and engage with familiar actors.

The emphasis was on recruiting interviews with transport operators or the transport authority, since these were groups that traditionally have a history of business-to-consumer customer relations in the public transport sector. The expert interviews were conducted in person, over the internet (i.e., Skype) and by telephone. It is recognized that each of these methods has advantages or disadvantages; Opdenakker (2006) notes that face-to-face interviews have "synchronous communication in both time and place", whereas telephone and internet-enabled conversations are only synchronous in time [30]. Mergel et al. (2019) further elaborated and demonstrated that face-to-face interviews make it possible for the 
interviewer and interviewee to exchange physio-social cues and to experiment the same environment at the same time, elements that are difficult to replicate or completely lost in an online or telephone interview [31]. However, logistical constraints sometimes necessitate the use of remote technologies.

Expert interviews were considered an important data collection method because transportation professionals and stakeholders in the mobility ecosystem that were not users would have a specific, experienced perspective in developing and applying transportation services. This is a view that is not possible to obtain from the typical user or citizen, who is only looking at transportation from their own personal needs (a concurrent investigation into factors affecting willingness-to-share in individual users and residents was assessed separately using focus groups). Newcomer et al. (2015) recommend a semi-structured interview format, in order to have the freedom to ask probing, open-ended questions, and so this was the structure of the questions and discussions [32].

\subsection{Development of Questions}

We asked the interviewees 15-25 questions, in conversations that ranged from 35 to $70 \mathrm{~min}$, to gain information regarding three core questions:

- What do transportation experts believe customers expect from future shared or autonomous public transport?

- Who do transportation experts believe is responsible for encouraging or increasing willingness-to-share in the public, when it comes to AVs?

- How could transportation stakeholders increase societal acceptance of dynamic ridepooling, in preparation for a shared AV future?

These questions were developed initially by the first author, then refined through discussion with the second and third authors. Consideration was taken in developing the questions because some of the interviewees were industrial competitors, and so the questions could not be overly specific to business practices that could arouse distrust or dislike of the discussion.

The interviews began by asking participants why they had selected to work in public transport, transitioned by asking their thoughts on the network of actors and influences in New South Wales regarding shared ride services and autonomous vehicle projects, their opinions on what residents or customers wanted from shared or autonomous transportation, and ended with their own personal attitudes towards car ownership, shared rides, and using AVs. The interviews were recorded, listened to by the first author and then transcribed and coded using Atlas.ti qualitative analysis software, in a process described by Gibbs (2007) as primarily concept-driven coding [33]. Additionally, there were two workshops held with TfNSW, discussing and evaluating the related focus group work with users and potential factors affecting willingness-to-share.

The coding followed a "top-down" approach; an initial list of codes was generated based on literature on dynamic ridepooling, ridehailing, carpooling, and similar shared mobility experiences (see Appendix A). These were used for the first pass of analysis. Additional codes were created during the analysis and read-through of the transcripts.

\section{Results}

This section describes findings from each of the three core research questions.

\subsection{What Do Transportation Experts Believe Customers Expect from Future Shared or Autonomous Public Transport?}

As shown in Table 1, four themes emerged in discussion of this first research question: reassurance/education, competitive pricing, safety/reliability/comfort, and convenience/ease of use. 
Table 1. What do transportation experts believe customers expect from future shared or autonomous public transport?

\begin{tabular}{ccccc}
\hline & $\begin{array}{c}\text { Reassurance; } \\
\text { Customer } \\
\text { Education }\end{array}$ & $\begin{array}{c}\text { Competitive } \\
\text { Pricing }\end{array}$ & $\begin{array}{c}\text { Safety, } \\
\text { Reliability, } \\
\text { or Comfort }\end{array}$ & $\begin{array}{c}\text { Convenience; } \\
\text { Ease of Use }\end{array}$ \\
\hline $\begin{array}{c}\text { Transport Authorities } \\
\text { Transport Operators }\end{array}$ & $\sqrt{ }$ & $\sqrt{ }$ & $\sqrt{ }$ \\
$\begin{array}{c}\text { Technology Providers } \\
\text { Academia }\end{array}$ & $\sqrt{ }$ & $\sqrt{ }$ & $\sqrt{ }$ \\
\hline
\end{tabular}

\subsubsection{Reassurance and Education}

Transport authorities, academics, and technology providers believed that users of the transport system needed further education or assurances in order to use on-demand and shared AVs effectively. Previous experience was considered the best education tool, and transport authorities saw little to no behavior problems from passengers once they had boarded an on-demand ride, even when the vehicle was very different in form from traditional larger vehicles. In the on-demand services, the transport authorities identified the misunderstanding of digital technology as a larger concern.

"This is relatively new. So we've had to do a lot of education, to get customers to even try the service. It's not something easy to understand, because it blends into the taxi mentality, which is never considered public transport. So, for them to shift their mindset from going to a bus stop, waiting for the bus, now all of a sudden we're offering this service where the vehicle comes to you, and that shift in mindset, it takes a bit of education."

The transport authorities and academics credited service operators like Uber for introducing the on-demand concepts to the general public, but the technology providers acknowledged a difficulty to capitalize on ridehailing acceptance into a gain for AV acceptance.

\subsubsection{Competitive Pricing}

Only two groups of interviewees mentioned pricing as integral to customer expectations: service operators and academics. Service operators acknowledged that there were differences when the on-demand services or AV pilots were offered through a governmentcontracted model versus a purely commercial service. Differences in business models enabled commercial operators more flexibility or creativity in creating their service offers, developing fleets, and attracting users, whereas operators delivering to TfNSW were given relatively attractive pricing standards (and in some cases, integrated digital payment in connection with TfNSW's fare system, Opal Pay), but lacked the ability to grow their vehicle supply or areas served to the same extent.

The academic interviewee was straightforward about customer expectations.

"Why do you share an Uber? It's because it's cheaper, isn't it? There's no other conceivable reason on Earth, why you would choose to increase your travel time getting a car with a stranger having convenience other than it saves you money."

This trade-off between price and convenience, when the shared ride options could be almost public transport ticket prices, offering nearly door-to-door service and the comfort of a smaller vehicle, was seen by the academic interviewee as the strongest and most significant possible factor.

\subsubsection{Safety, Reliability, Comfort}

Smaller vehicles as a function of service and comfort (and the chief benefit of services like Uber), was also mentioned by transport authorities with experience of different ondemand services and trials. An interviewee from the transport authority spoke about two on-demand trials in two different areas of Sydney: Inner West, which utilized small buses (Hino Poncho), and Northern Beaches, which relied on vans (Mercedes Sprinter; see 
Figure 2) and sport-utility vehicles. However, in their view, the vehicle format was not the only thing that influenced the safety, comfort, and expectations of the customer.

"The vehicle in the Inner West is much larger. It's a bus, like a cute little bus, versus the Toyota Rav 4 (in the Northern Beaches). But the difference is on Northern Beaches, it's a much more community feel. And historically public transport has been just nonexistent out there. Introducing something like Keoride is a godsend, so there's so much appreciation for such a service."

A vehicle manufacturer acknowledged that an advantage of the current $\mathrm{AV}$ models, which typically carry 10-15 passengers, was that the high roof and dominant glass panels created a sense of space and transparency about the ride experience. However, a transport operator did not know how to increase safety or comfort in shared mobility when the vehicles were smaller than most $\mathrm{AV}$ shuttles.

"In terms of how you make people more comfortable or better-behaved in shared taxis, I don't know. And the thing is, you always have the most vulnerable people in mind when you look at these services. It's obvious from the news and statistics that they're not being protected, sometimes from the driver, let alone the other passengers."

\subsubsection{Convenience, Ease of Use (for Disadvantaged Groups)}

Many of the service operators interviewed were offering on-demand transport or AV pilots in smaller suburbs or rural/regional locations, unlike other trials or pilots in other places in the world which tend to launch and demonstrate in dense, metropolitan zones. This meant that the operators interviewed were familiar with the challenges of transportation in places where public transport was historically poor or non-existent. However, since age and other physical challenges could limit a person's ability to drive, the service operator highlighted that early experiences from an $\mathrm{AV}$ pilot in a retirement community showed that older demographics would enjoy the relative comfort and convenience on-demand transport and AVs could offer.

Although most on-demand transport services rely heavily on digital infrastructure (apps) and familiarity with using smartphone technology, transport authorities acknowledged that many of their on-demand pilots and some of the AV trials were in smaller towns with older populations-demographics that typically have lower smartphone usage and rely more on traditional telephone bookings. According to one transport authority representative:

"What we know from our 11 trials, is that they, the customers, don't necessarily need an app to work. They're happy to phone in. And generally, it's small towns, it's much more personalised. They're happy to have a chat with somebody on a phone line."

\subsection{Who Do Transportation Experts Believe Is Responsible for Encouraging or Increasing} Willingness-to-Share, When It Comes to AVs?

There was a spread of views on who was most responsible or had the most resources and potential for shaping public attitudes and increasing the acceptance of shared, ondemand and eventually autonomous mobility, as shown in Table 2.

Transport authorities believed it was nearly everyone's responsibility: authorities, operators, and technology providers alike. Public transport operators believed most of the responsibility lay with government agencies and in policies both directly related to the point-to-point industry as well as actions that would discourage private car ownership, but that they themselves also needed to create more attractive services to satisfy current customers and future users. Interestingly, the technology providers thought government authorities needed to be more proactive and stressed that the education of current and future customers was something only the transport authority could provide, and that much more efforts were needed. 


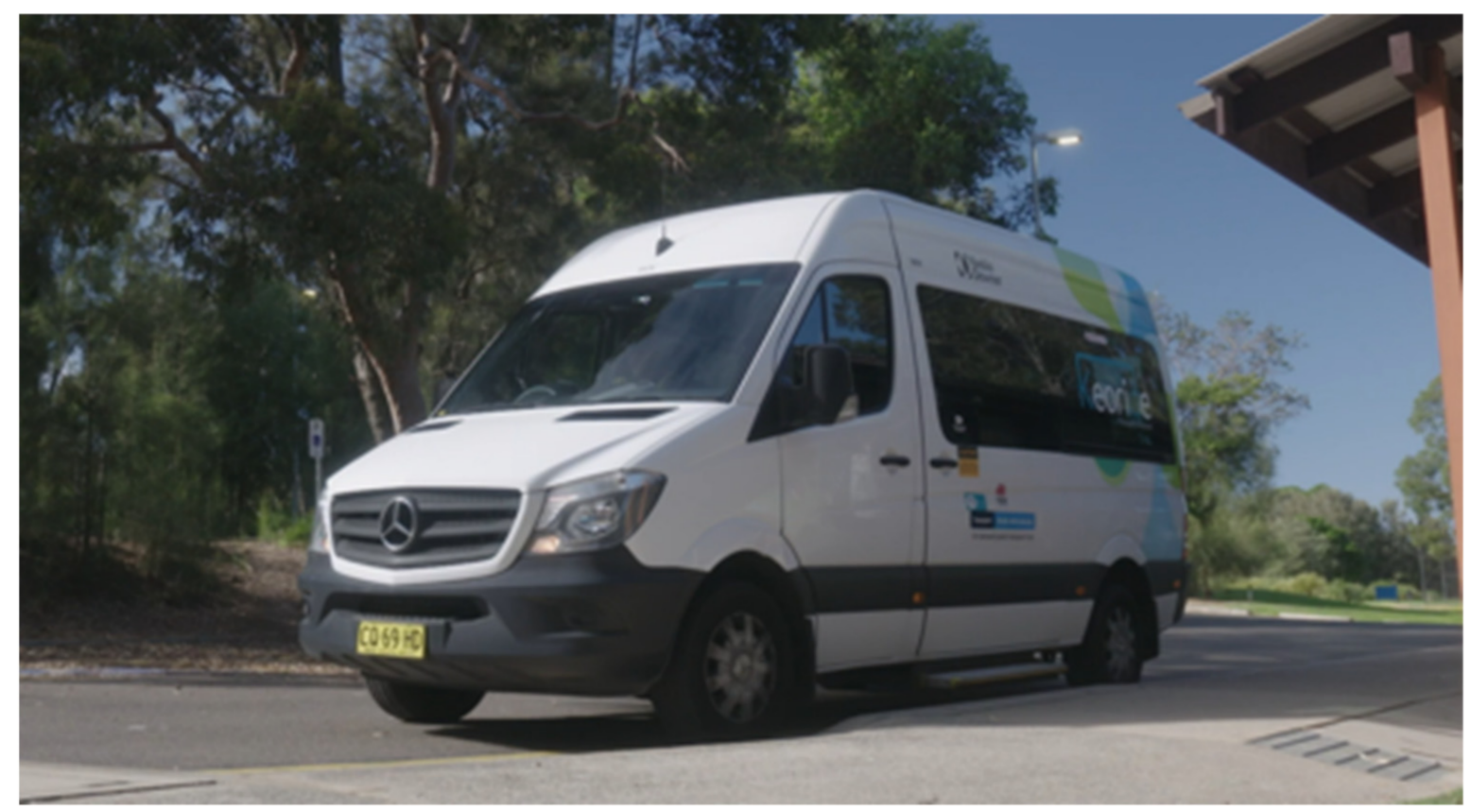

Figure 2. A Keoride vehicle in the Northern Beaches of Sydney, NSW. Photo courtesy of Keolis Downer.

Table 2. Who do transportation experts believe is responsible for encouraging or increasing willingness-to-share, when it comes to AVs?

\begin{tabular}{|c|c|c|c|c|}
\hline & & \multicolumn{3}{|c|}{$\ldots$ are the Responsible Actors } \\
\hline & & $\begin{array}{c}\text { Transport } \\
\text { Authorities }\end{array}$ & $\begin{array}{l}\text { Transport } \\
\text { Operators }\end{array}$ & $\begin{array}{c}\text { Technology } \\
\text { Providers }\end{array}$ \\
\hline $\begin{array}{c}\text { Transport Authorities } \\
\text { Transport Operators } \\
\text { Technology Providers } \\
\text { Academia }\end{array}$ & believed ... & $\begin{array}{l}\sqrt{ } \\
\sqrt{ } \\
\sqrt{ }\end{array}$ & $\begin{array}{l}\sqrt{ } \\
\sqrt{ } \\
\sqrt{ }\end{array}$ & $\begin{array}{l}\sqrt{ } \\
\sqrt{ }\end{array}$ \\
\hline
\end{tabular}

The academic interviewee believed price and vehicle comfort to be two factors most likely to increase acceptance of shared mobility. They believed that ride pricing was the responsibility of the operator or technology provider, and that vehicle comfort was the domain of technology providers (particularly AV manufacturers).

The transport authorities believed they had responsibility for shaping public opinion, but tended to view their efforts as best done by de-regulating the existing taxi legislation and encouraging transport operators and technology providers to submit their own proposals and suggestions for where on-demand or AV pilots should take place; in short, they viewed their crucial role as one to make the environment easier to enter for all services.

"When we designed this program, we wanted to make it quite flexible. So, very different to how we generally do government contracts. It was a very open request for expressions of interest, where we say, this is the model we want to set out, we want to set up a demand responsive transport service. And the operator would tell us where they think interest is good, how it should work, and what technology they proposed to us. We felt that the market knew better what the needs and wants were."

4.3. How Could Transportation Stakeholders Increase Societal Acceptance of Dynamic Ridepooling, in Preparation for Shared, On-Demand Autonomous Vehicles?

Different interviewees had a range of views to the third core question. The technology providers and public transport operators were generally pleased with the market-first approach of TfNSW, although some of the operators suggested that transport authorities 
could do more in other areas to suppress the desire to drive into Sydney's central business district (i.e., make parking more expensive, increase taxes for vehicle ownership) and thus increase willingness-to-share on-demand transport. Such a 'carrot-and-stick' approach, offering shared mobility services while restricting parking and increased parking fees as policy was also suggested as in line with plans by some of the transport authorities.

The transport authorities themselves were quite proud of their open-approach to simplifying regulation and believed doing so had helped a number of commercial ondemand technology providers enter the market, although as of the end of 2019, only one of them, Uber, offered a shared ride option. According to one transport authority interviewee:

"The Point to Point transport reforms in New South Wales were reasonably significant; they are a simpler model than applied in other states. And certainly, if you talk to anyone in the industry, they like the way the regulator gives them access to information so they can manage the safety obligations in terms of the driver vehicles. And it's very much now focused on safety. We don't get into any quality regulations; they lifted all those. So, it's up to the businesses to sort of set themselves apart by offering particular service offerings."

This view gave the impression that the transport authorities believed that if the commercial entities were not competing in the dynamic ridepooling space, then there was not necessarily demand for it. Transport authorities also believed that users' previous experience with public transport, and some experience with services like UberPool had already done much to educate people on how to share rides comfortably. They also pointed out that the wide net they had cast, with a variety of pilots and trials throughout the state, was proof that the Future Transport 2056 strategy was working; for example, through the different pilots and technology providers it had become clear some software was better at aggregating rides more effectively than others, and TfNSW was using the learnings from the trials to offer permanent, viable on-demand transport in new suburbs of Sydney.

However, other interviewees from the transport authorities felt there was still ambiguity about where shared mobility could fit into the entire public transport offer, and that on top of what level of service was even possible to provide there was a communication and educational challenge for the public.

"One of the things that we're not clear about is where it feeds in the broader transport system. So far, point to point services have been largely a commercial offering, and now we're talking government subsidising an on-demand offering. If you live on the stretches of Sydney, you probably have a sense that you're not going to have bus service, or you will have a pretty infrequent service, because you just haven't got the population. I think we need to be able to communicate to the public better where on-demand is provided, why, and when. And we don't have that solved yet."

Compared to the other stakeholder groups interviewed, the representative of the academic sector was much more pessimistic than the transport operators, transport authorities, or technology providers, arguing that the social anxiety of co-occupying a limited shared space with an previously unknown passenger is a much bigger disincentive than embracing new technologies towards a shared autonomous future.

"Getting into a vehicle with a stranger in a small space with no driver, for many segments of society, is going to be a quantum leap. Getting in a vehicle without a driver is going to be a big enough challenge for people, but having to share with someone else, someone that you don't know, I think is enormous."

\section{Discussion}

Based on interview results, it seems that interviewees from transport authorities consider that people know how to share and are already comfortable about sharing with strangers (although it must be acknowledged that this is a finding specifically in a preCOVID-19 context) thanks to their exposure to on-demand ridehailing services like UberPool. Several members of the transport authority suggested that by removing regulations 
so that more commercial transport operators could enter the on-demand space, they had increased the presence and thus public acceptance of on-demand and shared mobility in the region. This was somewhat of a misconception, since at the time of the interviews, there were several commercial on-demand services in New South Wales, but only one (Uber) offered any shared ride product (UberPool).

Pricing is an important factor discussed frequently by transport operators and emphasized by the academic interviewee, but it was barely discussed by public transport authorities. At the time of the interviews, the autonomous vehicle pilots did not cover large distances and were free to the public; similarly, the on-demand transport pilots charged conventional public transport fares. Thus pricing, and its potential to motivate specific segments of the population, was not particularly discussed by the transport authorities. While they mentioned that the pilots and demonstrations were subsidized by the state, they did not elaborate on criteria for that subsidy or expectations for how long it should last. However, the academic expert who was interviewed felt very strongly that price was the only method to encourage citizens to try dynamic ridepooling services, and that price sensitivity would counter negative experiences or an otherwise decreased willingness-toshare. This view was echoed in Quarles and Kockelman's (2018) work about American attitudes towards electric, shared, and self-driving vehicles whey they note: "willingness to share is linked with willingness to pay, because people are less willing to share rides with strangers and require the financial incentive to do so; this suggests that a significant cultural shift may be needed to reduce private vehicle ownership" (p.16) [34].

Additionally, other members of the transport authorities viewed a larger struggle in educating the public to use on-demand transport, since "on-demand" did not fit with the public's perception of public transport. Stakeholders felt that the public viewed on-demand transport as less reliable than on-demand ridehailing, because the comparatively larger fleet availability with Uber or Ola meant shorter wait times and larger service areas. It seems while TfNSW had succeeded in diversifying the mobility offer, they had not been able to reap the same kind of benefits or acceptance for on-demand public transport as they had for on-demand ridehailing. Lavieri and Bhat (2019) were able to show that "getting an individual to try pooled ridehailing just one time can have a lasting impact on the frequency of ridehailing over the longer term" [22]. This may mean that public transport authorities need to prioritize the introduction of on-demand public transport into communities before permitting the introduction of commercial, on-demand ridehailing.

When it came to understanding who was "most responsible" for increasing public acceptance of shared mobility, autonomous vehicles, and eventually shared autonomous vehicles, it was not a surprise that both transport authorities and transport operators were identified as such by other stakeholders. Interestingly, although technology providers (such as commercial on-demand ridehailing services) were viewed as the "least responsible" for shaping public opinion, the transport authorities strongly highlighted the belief that by removing regulation and freeing the market, they had created an environment that would increase mobility options and access to such services by the public. The strong actions towards deregulation by the transport authorities empowered commercial service operators, but this was the stakeholder group with the least perceived responsibility for increasing the acceptance of shared mobility (and eventually shared autonomous transport), pointing to a potential gap in action-impact.

Previous research within this project has shown that there is a strong level of concern, fear, or anxiety on the part of potential passengers when it comes to dynamic ridepooling in an autonomous, driverless vehicle-even those who are accepting and comfortable with dynamic ridepooling. The strong level of concern was not about uncertainty regarding autonomous vehicle technology, which has been the focus of previous studies; rather, "sharing anxiety" was centered around the authority vacuum and the potential behavior of other passengers in a shared, driverless vehicle.

Yet, the potential behavior of other passengers in a shared driverless vehicle was a safety concern that did not seem to present itself with the interviewed stakeholders. Almost 
none of the interviewees addressed the potential of "sharing anxiety" by passengers in the vehicle; it was only one transport operator and the academic interviewee who were explicit in describing the potential emotional conflict of users during their ride experience; the academic interviewee pointed out that sharing a small space with a stranger was an uncomfortable social setting that had only been thus far mitigated by deeply discounted travel prices.

This lack of visualization about concerns in-ride from future users, coupled with an optimistic perspective that contemporary dynamic ridepooling services like UberPool had done enough to educate riders on the etiquette of sharing, is one of the most significant findings from the interviews. It is this lack of strong consideration of the socio-technical system to be the "sharing trap" that awaits transport authorities and the mobility industry.

As the COVID-19 global pandemic spread in 2020, the issues of increasing the public acceptance of sharing become even more complex. The technological anxiety and safety concerns already mentioned, along with the potential for sharing anxiety caused by an authority vacuum in a driverless vehicle, would only be amplified by fears of infection spread by unknown persons in public spaces. Planned research will examine the scale of how acute sharing anxiety is when introduced to biosecurity concerns, and what potential areas of service management (e.g., sanitation) or vehicle design (e.g., use of materials) could be used to address these concerns. This research so far has only investigated elements of service offers and related policy recommendations, but in view of current or future public health crises, there is new urgency for consideration of interior vehicle layout and how that contributes to restoring trust and confidence in the safety of public spaces, and issues surrounding personal data for contact tracing.

\section{Policy Recommendations}

It is striking that very few of the interviewees acknowledged "sharing anxiety" as a potential barrier to acceptance. This may be indicative of an overly optimistic view of people embracing new mobility services and shared autonomous vehicles. Our findings from these interviews suggest that there is a socio-technical systems gap; the experts, who come from technical backgrounds, tend to focus on technological acceptance of AVs. At the macro level, this disconnect between government policies, operator desires, and end user acceptance were identified as a key limitation to transitioning to shared autonomous public transport.

For shared transport to prosper, a multilevel approach to planning and implementation must be employed; it is not enough to create an open market for more mobility entities to operate or to invest in technological innovation. In order to overcome this sharing barrier, a number of potential strategies and policies could be employed, particularly by the transport authorities. We present six recommendations across two categories: first, in ODT pilot selection and creation, and secondly, in how TfNSW interacts, regulates, and supports TNCs.

\subsection{ODT Policy Recommendations}

We make three recommendations for changes in how TfNSW evaluates existing regions and creates ODT pilots: identify potential sites by locating areas with high rates of vehicular accidents; giving pilots multi-year contracts in order to become culturally established; integrating ODT services within TfNSW's payment network with a standardized, geofenced app interface.

- Identify potential sites for ODT pilots by locating areas with high rates of vehicular accidents, to evaluate shared mobility service potential for accident reduction

In our work reviewing the literature and in our interviews with stakeholders, typically slow-to-adopt users, such as the elderly, are more motivated to try dynamic ridesharing or AVs if they had personally experienced a vehicular accident. Identifying regions with high numbers of single-occupancy vehicle accidents and promoting ODT there may improve safety and increase community acceptance of new mobility services. 
- ODT pilots likely need longer time periods to become culturally established (potentially multiple years)

On demand transport requires fundamental behavioral change in how customers access transport services. Whether this is getting people out of cars onto public transport or getting people used to accessing bus services in a different way, changing customer behavior is critical. Surveys show that once customers try ODT, they are generally very satisfied [35], and the focus groups with the Keoride pilots also indicated high levels of satisfaction, even a sense of community enjoyment out of the service [9]. However, riders themselves described how they had to be persuaded to try it first, or just happened to discover it by seeing the Keoride-branded vehicles drive by them on the street.

- ODT services may need to be more fully integrated into the TfNSW payment services, possibly in the form of a standardized geofenced app interfaced that could be used in any New South Wales region across different services

Transport providers and operators highlighted the importance of integrating on demand public transport options with TfNSW's journey planning, ticketing and payment system. Not only does this coincide with TfNSW's agenda for MaaS, but enabling a single app throughout New South Wales (instead of the current system, which may allow for simplified payment, but a multitude of region-dependent apps) would simplify journey planning and standardize the experience for users, increasing their ability to understand the public transport system, as well as to adopt new methods of travel and to encourage the replication of their experience among friends and family. This 'word of mouth' encouragement and education surfaced as a motivating factor in every focus group with at least one participant, but it is difficult for persons to explain their experience to friends and family in other neighborhoods, when the transport apps they use vary so widely, and the service parameters are different for each region.

\subsection{Policy Recommendations for Regulating TNCS}

We make three recommendations for changes in how TfNSW interacts with TNCs: petitioning for demographic user data based on which product is used (private ridehailing versus dynamic ridepooling); strongly encouraging TNCs to offer dynamic ridepooling as a product in their services via tax incentivization; tracking incidents with the Point-to-Point Commission by adding a category for shared rides; examining consequences and deterrents for "bad behavior" by users, marketed and enforced by TNCs.

- Petition for demographic user data from TNCs based on their service usage (private trip ridehailing, versus dynamic ridepooling)

An additional source of data could be generated if the Point-to-Point Commission were to require anonymized user demographics from TNCs in order to understand who is currently using ridehailing, and who specifically is currently using dynamic ridepooling. Future work to develop mobility personas (similar to work done in MERGE Greenwich and with TUM-CREATE in Singapore) will add to the understanding of who is willing to share mobility services in both a contemporary definition (with a driver) and in future, driverless vehicle scenarios. While this information is sensitive between competing TNCs, TfNSW (as a government agency which serves the public) has a right to understand where shared mobility is being more readily used and accepted.

- TfNSW could encourage TNCs to offer dynamic ridepooling as part of their ridehailing services (if they do not already offer it) and to promote existing shared ride services through tax incentivization

Transport providers, operators, and manufacturers all praised the transport authority for taking such an open-field, market friendly approach to ridehailing and on demand services, and dismantling a number of outdated or cumbersome regulatory hurdles to allow for faster entry of new commercial competitors. However, while there are half a dozen current entrants of on demand ridehailing in New South Wales, only Uber and Didi 
offer a shared mobility option. If Transport for New South Wales required TNCs (not taxis or limo services) to offer a shared mobility product alongside their private ridehailing service, like UberPool or DidiShare, the availability, awareness and exposure of dynamic ridepooling would increase in the population.

- Point-to-Point Transport Commission could consider tracking incidents that took place in shared, pooled rides, by adding a sub-category to D or creating an F category to the current incident reporting model

Requiring a shared mobility product, which could be a burden for some TNCs, would also mean TfNSW would need to make adjustments to the tracking system for complaints and incidents that are logged by the Point-to-Point Transport Commission to explicitly include incidents between passengers in shared rides. A transparent process for the public as to how these complaints are registered is currently lacking, as is information about the potential fines or consequences for passengers who misbehave during shared rides. While this could be viewed as a police matter (punitive), the data collection of these incidents would be extremely beneficial in understanding how to design better services that lower the potential for conflict (preventative).

\section{Conclusions}

This paper focused on collected interviews with transportation experts, professionals and stakeholders from TfNSW, the Point-to-Point Transport Commission, public transport operators, technology providers (AV manufacturers) and academics in New South Wales, Australia, on the topic of shared mobility and future shared autonomous public transport. These interviews revealed a need to develop strategies and enact policies to build up individual and societal willingness-to-share rides, and a potential underappreciation for the problem that low acceptance of shared mobility today could create for future shared autonomous public transport.

It is necessary, and in these uncertain times, increasingly urgent for the elements of 'sharing anxiety' - fear of an authority vacuum, discomfort with strangers, lack of established shared-riding culture, and lack of established process when those cultural norms are violated - to be addressed in order to increase the acceptance of on-demand, and eventually autonomous, transport. Concerns about what happens inside of a smaller public space will only be heightened during times of pandemic and other health crises. As mentioned in in Zhang's (2019) research on ridesharing attitudes in China, mutual trust is an important aspect in Western societies, but the cultural differences between countries in respect to herd behavior, personal space or shame when deviating from cultural norms need to be explored further [36].

This could include heavy promotion and publicization of the societal, environmental and personal benefits of dynamic ridepooling in conventional vehicles, which could have significant impact on the normalization of contemporary mobility services. More policy interventions around pricing should be considered to encourage more collective (i.e., pooled) travel in the future; for example, some cities impose a ride or road tax on ridehailing companies as part of the agreement for them to operate in an urban area. Transport authorities could waive this fee for dynamic ridepooling services, and create other tax incentives for commercial on-demand services in order to encourage them to offer and promote ridepooling products, a recommendation from Compostela et al. (2020)'s work on the costs of automated, electrified, and shared mobility in the United States [37]. Additionally, with innovation funding, government funds for technological or social AV research should prioritize results or use cases that focus on shared autonomous public transport, over commercial vehicles that are meant for private or individual consumption.

Understanding how to develop and leverage mobility services around potential consumer concerns and barriers can increase the sense of safety and shareability in shared AVs and automated public transport. Transport stakeholders have a unique opportunity to avoid "the sharing trap" as they prepare for a shared autonomous public transport future. 
Author Contributions: S.D.: funding acquisition, project administration, conceptualization, methodology, data curation, formal analysis, writing - original draft preparation. J.D.N.: conceptualization, writing-reviewing and editing, supervision. Y.Z.W.: conceptualization, formal analysis, writingreviewing and editing. All authors have read and agreed to the published version of the manuscript.

Funding: This research was funded by Vinnova, the Swedish innovation agency, grant number 2018-04063. The research team was also provided a grant by Transport for New South Wales to University of Sydney Business School, without which the work would not have been possible.

Institutional Review Board Statement: The study was conducted according to the guidelines of the Declaration of Helsinki, and approved by Chalmers University of Technology, in accordance with the Swedish Ethical Review Act (SFS 2003:460).

Informed Consent Statement: Informed consent and signed release forms were obtained from all subjects involved in the study.

Data Availability Statement: Transcriptions and audio records of the interviews can be found with the first author and will be stored until December 2022, at the conclusion of the Vinnova project.

Acknowledgments: This research also relied on the generosity of Transport for New South Wales and KeolisDowner for participating and recruiting interviewees. Many thanks to MariAnne Karlsson and Helena Strömberg for their guidance, and to Giannis Fyrogenis and Jillian Fernandez for their contributions with feedback, editing and support.

Conflicts of Interest: The authors declare no conflict of interest.

\section{Appendix A}

\section{List of Interview Questions}

1. What drew you to a career in public transport?

2. Why did you want to work with autonomous vehicles or shared mobility?

3. What about in the act, where they define different passenger services: how are shared rides treated in the framework of taxi services? Or does it not matter?

4. What do you think customers want from shared, on-demand or autonomous public transport?

5. What kind of harassment or safety complaints have you logged since opening the transportation system to these kinds of services?

6. Do you think that will change for the better or for the worse with autonomous vehicles?

7. Why did you select this location for testing autonomous vehicles, or shared ride services?

a. What was the process behind selecting a location?

b. What was special about this area-the population? The physical location? The route?

c. What kind of investigation did you to do confirm the choice: surveys with potential users, workshops with city officials?

d. How was the project funded?

e. Which city/regional/government actors were interested in this project?

f. What was the initial reaction of the city when you proposed this project?

g. What is your definition of success for this project?

8. What factors do you think contribute to the success of this project? Is it national economy? Is it technology?

9. What kind of data is collected during the rides?

a. Where do you collect data about user experiences during the rides?

b. Where do you collect data about daily ridership or usage during bad weather?

10. What do you think are the biggest threats to projects like this?

11. What do you think are the best opportunities or resources for increasing shared rides, or autonomous vehicles? 
a. The environment/environmental groups?

b. Government/politicians?

c. New urban plans?

d. Other-please explain

12. If you could change anything about this project, or if you had to start this project again in a new city, what would you change or do differently?

a. If you could choose the next city for autonomous public transport, where would it be and why?

13. How can we convince people that autonomous vehicles should be shared, just like public transport is shared today?

a. What do you think about ridesharing services today, like UberPool?

14. When it comes to setting up projects in Australia, do you think certain states are more innovative or excited to set up projects than others? How would you describe the readiness of the different governments: eager, or conservative?

a. What kind of things do you wish the government was doing to help public transport and help autonomous vehicles?

15. Do you personally own a car for everyday use?

a. If so, do you think you would give up your car if you lived near autonomous transport? Or do you think that would be a difficult transition for your family?

16. Do you have children? If so,

a. Have they ridden in an autonomous vehicle?

b. Would you ever let them in a shared ride service like UberPool?

\section{References}

1. Fulton, L.; Mason, J.; Meroux, D. Three Revolutions in Urban Transportation-How to Achieve the Full Potential of Vehicle Electrification, Automation and Shared Mobility in Urban Transportation Systems around the World by 2050. Available online: https:/ / steps.ucdavis.edu/wp-content/uploads/2017/05/STEPS_ITDP-3R-Report-5-10-2017-2.pdf (accessed on 13 November 2018).

2. Morris, E. From horse power to horsepower. Access Mag. 2007, 1, 2-10.

3. Mulley, C.; Nelson, J.D. (Eds.) Urban Form and Accessibility: Social, Economic, and Environment Impacts, 1st ed.; Elsevier: Amsterdam, The Netherlands, 2020; ISBN 9780128198223.

4. Fraedrich, E.; Heinrichs, D.; Bahamonde-Birke, F.J.; Cyganski, R. Autonomous driving, the built environment and policy implications. Transp. Res. Part A Policy Pract. 2019, 122, 167. [CrossRef]

5. Zhao, J. Humanizing Travel: Investigating the User Identification of, Attitude Towards and Preference for Dynamic Ridesharing Services (No. MITR25-18); New England University Transportation Center, Massachussets Institute of Technology: Cambridge, MA, USA, 2017.

6. Sarriera, J.M.; Álvarez, G.E.; Blynn, K.; Alesbury, A.; Scully, T.; Zhao, J. To share or not to share: Investigating the social aspects of dynamic ridesharing. Transp. Res. Rec. 2017, 2605, 109-117. [CrossRef]

7. Aarhaug, J.; Olsen, S. Implications of ride-sourcing and self-driving vehicles on the need for regulation in unscheduled passenger transport. Res. Transp. Econ. 2018, 69, 573-582. [CrossRef]

8. Sanguinetti, A.; Kurani, K.; Ferguson, B. Is It OK To get in a Car with a Stranger? Risks and Benefits of Ride-Pooling in Shared Automated Vehicles; University of California Institute of Transportation Studies: Berkeley, CA, USA, 2019. [CrossRef]

9. Dolins, S.; Strömberg, H.; Wong, Y.; Karlsson, M. Sharing Anxiety Is in the Driver's Seat: Analyzing User Acceptance of Dynamic Ridepooling and Its Implications for Shared Autonomous Mobility. Sustainability 2021, 13, 7828. [CrossRef]

10. Metz, D. Developing Policy for Urban Autonomous Vehicles: Impact on Congestion. Urban Sci. 2018, 2, 33. [CrossRef]

11. Neoh, J.G.; Chipulu, M.; Marshall, A. What encourages people to carpool? An evaluation of factors with meta-analysis. Transportation 2015, 44, 423-447. [CrossRef]

12. Wong, Y.Z.; Hensher, D.A.; Mulley, C. Mobility as a service (MaaS): Charting a future context. Transp. Res. Part A Policy Pract. 2019, 131, 5-19. [CrossRef]

13. Bansal, P.; Kockelman, K.M.; Singh, A. Assessing public opinions of and interest in new vehicle technologies: An Austin perspective. Transp. Res. Part C Emerg. Technol. 2016, 67, 1-14. [CrossRef]

14. Shaheen, S.; Cohen, A.; Chang, A. Definitions for Terms Related to Shared Mobility and Enabling Technologies; SAE International: Warrendale, PA, USA, 2018. 
15. Fagnant, D.J.; Kockelman, K. Preparing a nation for autonomous vehicles: Opportunities, barriers and policy recommendations. Transp. Res. Part A Policy Pract. 2015, 77, 167-181. [CrossRef]

16. Moody, J.; Middleton, S.; Zhao, J. Rider-to-rider discriminatory attitudes and ridesharing behavior. Transp. Res. Part F Traffic Psychol. Behav. 2019, 62, 258-273. [CrossRef]

17. Dia, H.; Javanshour, F. Autonomous Shared Mobility-On-Demand: Melbourne Pilot Simulation Study. Transp. Res. Procedia 2017, 22, 285-296. [CrossRef]

18. Barbour, N.; Menon, N.; Zhang, Y.; Mannering, F. Shared automated vehicles: A statistical analysis of consumer use likelihoods and concerns. Transp. Policy 2019, 80, 86-93. [CrossRef]

19. Abraham, H.; Lee, C.; Brady, S.; Fitzgerald, C.; Mehler, B.; Reimer, B.; Coughlin, J.F. Autonomous Vehicles, Trust, and Driving Alternatives: A Survey of Consumer Preferences; Massachusetts Inst. Technol, AgeLab: Cambridge, MA, USA, 2016.

20. MERGE Greenwich: Autonomous Ride-Sharing Vehicles, the Future of Urban Transport. 2017. Available online: https:// mergegreenwich.com/ (accessed on 6 June 2019).

21. Ho, C.Q.; Mulley, C.; Hensher, D.A. Public preferences for mobility as a service: Insights from stated preference surveys. Transp. Res. Part A Policy Pract. 2019, 131, 70-90. [CrossRef]

22. Lavieri, P.S.; Bhat, C.R. Investigating objective and subjective factors influencing the adoption, frequency, and characteristics of ride-hailing trips. Transp. Res. Part C Emerg. Technol. 2019, 105, 100-125. [CrossRef]

23. Delbosc, A.; McDonald, N.; Stokes, G.; Lucas, K.; Circella, G.; Lee, Y. Millennials in cities: Comparing travel behaviour trends across six case study regions. Cities 2019, 90,1-14. [CrossRef]

24. Cohen, S.; Shirazi, S.; Curtis, T. Can We Advance Social Equity with Shared, Autonomous and Electric Vehicles? Institute of Transportation Studies at the University of California: Davis, CA, USA, 2017.

25. Narayanan, S.; Chaniotakis, E.; Antoniou, C. Shared autonomous vehicle services: A comprehensive review. Transp. Res. Part C Emerg. Technol. 2020, 111, 255-293. [CrossRef]

26. Smith, G.; Hensher, D.A. Towards a framework for Mobility-as-a-Service policies. Transp. Policy 2020, 89, 54-65. [CrossRef]

27. Golbaebi, G. Individual predictors of autonomous vehicle public acceptance and intention to use: A systematic review of the literature. J. Open Innov. Technol. Mark. Complex. 2020, 6, 106. [CrossRef]

28. Transport for NSW. Future Transport 2056 Strategy. NSW Government. 2018. Available online: https:/ / future.transport.nsw.gov. au/sites/default/files/media/documents/2018/Future_Transport_2056_Strategy.pdf (accessed on 29 October 2019).

29. Biernacki, P.; Waldorf, D. Snowball Sampling: Problems and Techniques of Chain Referral Sampling. Sociol. Methods Res. 1981, 10, 141-163. [CrossRef]

30. Opdenakker, R. Advantages and disadvantages of four interview techniques in qualitative research. Forum Qual.Sozialfor./Forum Qual. Soc. Res. 2006, 7, 11.

31. Mergel, I.; Edelmann, N.; Haug, N. Defining digital transformation: Results from expert interviews. Gov. Inf. Q. 2019, 36, 101385. [CrossRef]

32. Newcomer, K.E.; Hatry, H.P.; Wholey, J.S. Conducting semi-structured interviews. In Handbook of Practical Program Evaluation; Wiley: Hoboken, NJ, USA, 2015.

33. Gibbs, G.R. Thematic Coding and Categorizing. Analyzing Qualitative Data; Sage: London, UK, 2007; pp. $38-56$.

34. Quarles, N.; Kockelman, K.M. Americans' Plans for Acquiring and Using Electric, Shared, and Self-Driving Vehicles 2. In 2018 Annual Meeting; Transportation Research Board: Washington, DC, USA, 2018; Volume 6972, pp. 1-17.

35. Mageean, J.; Nelson, J. The evaluation of demand responsive transport services in Europe. J. Transp. Geogr. 2003, 11, 255-270. [CrossRef]

36. Zhang, P. Happy Rides Are All Alike; Every Unhappy Ride Is Unhappy in Its Own Way Passengers' Emotional Experiences While Using a Mobile Application for Ride-Sharing. In Proceedings of the International Conference on Information, Washington, DC, USA, 31 March-3 April 2019; pp. 706-717.

37. Compostella, J.; Fulton, L.M.; De Kleine, R.; Kim, H.C.; Wallington, T.J. Near-(2020) and long-term (2030-2035) costs of automated, electrified, and shared mobility in the United States. Transp. Policy 2020, 85, 54-66. [CrossRef] 